\title{
Review \\ Nitric oxide and cardiovascular effects: new insights in the role of nitric oxide for the management of osteoarthritis
}

\author{
Isla S Mackenzie, Daniel Rutherford and Thomas M MacDonald
}

Hypertension Research Centre (HRC) and Medicines Monitoring Unit (MEMO), Division of Medicine and Therapeutics, University of Dundee, Dundee DD1 9SY, UK

Corresponding author: Isla S Mackenzie, I.S.Mackenzie@dundee.ac.uk

Published: 17 October 2008

This article is online at http://arthritis-research.com/supplements/10/S2/S3

(c) 2008 BioMed Central Ltd

Arthritis Research \& Therapy 2008, 10(Suppl 2):S3 (doi:10.1186/ar2464)

\begin{abstract}
Nitric oxide (NO) is an important mediator in both health and disease. In addition to its effects on vascular tone and platelet function, it plays roles in inflammation and pain perception that may be of relevance in osteoarthritis. Many patients with osteoarthritis take nonsteroidal anti-inflammatory drugs (NSAIDs) long term for pain control. Over recent years concern has been raised about the possible cardiovascular side effects of NSAIDs. The reasons for this possible increased cardiovascular risk with NSAIDs are not yet entirely clear, although changes in blood pressure, renal salt handling and platelet function may contribute. Recently, drugs that chemically link a NSAID with a NO donating moiety (cyclo-oxygenase-inhibiting NO-donating drugs [CINODs]) were developed. NO is an important mediator of endothelial function, acting as a vasodilator and an inhibitor of platelet aggregation, and having anti-inflammatory properties. The potential benefits of CINODs include the combination of effective analgesic and anti-inflammatory actions with NO release, which might counterbalance any adverse cardiovascular effects of NSAIDs. Effects of CINODs in animal studies include inhibition of vasopressor responses, blood pressure reduction in hypertensive rats and inhibition of platelet aggregation. CINODs may also reduce ischemic damage to compromised myocardial tissue. In addition, endothelial dysfunction is a recognized feature of inflammatory arthritides, and therefore a drug that might provide slow release of $\mathrm{NO}$ to the vasculature while treating pain is an attractive prospect in these conditions. Further studies of the effects of CINODs in humans are required, but these agents represent a potential exciting advance in the management of osteoarthritis.
\end{abstract}

\section{Introduction}

Recently issued guidelines for the management of osteoarthritis [1] have emphasized the use of lifestyle advice, weight loss, and exercise as first-line interventions in the management of osteoarthritis, followed by the addition of paracetamol or topical nonsteroidal anti-inflammatory drugs (NSAIDs). However, many patients with osteoarthritis will require the use of systemic NSAIDs for control of their pain.
Recently, NSAIDs (both traditional and cyclo-oxygenase [COX]-2 selective) were linked to an increased incidence of cardiovascular events, at least in patients at increased baseline cardiovascular risk [2-5]. The degree of the risk associated with the various NSAIDs and the mechanisms underlying the link with cardiovascular events are still being investigated in large clinical trials. Findings to date have had a major influence on the use of these drugs in the management of chronic arthritic conditions, with regulatory authorities advising against the use of these drugs in patients with known cardiovascular disease or who are at high cardiovascular risk. However, many patients rely on NSAIDs to achieve adequate pain relief, and the risk/benefit ratio must be carefully considered when deciding whether to prescribe these agents. Options to ameliorate or counteract the risk associated with chronic use of NSAIDs in patients with arthritis would be welcome.

Nitric oxide (NO) is an important endogenous mediator of vasodilatation, also having effects on platelet function, inflammation, and pain perception. NO is also released from some drugs, historically nitrates, but more recently other agents that have been specifically designed to contain a NO moiety, which is released enzymatically in tissues and plasma. One approach that might ameliorate the cardiovascular risk associated with NSAIDs would be to use NSAIDs that also release $\mathrm{NO}$, namely the cyclo-oxygenase inhibiting nitric oxide donating drugs (CINODs). NO may also have other effects on the vasculature, including improvements in endothelial function and vascular tone, as well as effects on platelet aggregation. The link between atherosclerosis and chronic inflammation is increasingly recognized, with suggestions made that systemic inflammatory conditions such as rheumatoid arthritis also affect the vasculature, leading to a 
greater incidence of cardiovascular events. Data reported thus far suggest that NO may have a complex mixture of positive and negative effects on inflammation and pain in osteoarthritis; therefore, the role played by CINODs in this condition remains to be determined.

In this article we review the importance of $\mathrm{NO}$, and the effects of NSAIDs on blood pressure and endothelial function, and we explore the possible roles played by NO and CINODs in osteoarthritis.

\section{Endothelium and nitric oxide Historical perspective}

NO-releasing drugs have been in use for about 150 years and now include the organic nitrates, sodium nitroprusside and nicorandil. The first organic nitrate, glyceryl trinitrate (GTN), was originally synthesized in 1847 by the Italian chemist Ascanio Sobrero. He observed that small amounts of GTN placed on the tongue caused a violent headache, which led Constantin Hering to pursue the development of GTN as a homeopathic remedy for headache [6]. In 1867 the British physician Lauder Brunton observed that the related compound amyl nitrite could be used to provide pain relief in angina. In 1879, William Murrell reported that a $1 \%$ solution of GTN was effective as both an acute antianginal agent and as prophylaxis against angina [7], and the use of GTN and other nitrates was later extended to the management of severe hypertension and heart failure. Even in these early years it was clear that nitrate therapy was hampered by the development of nitrate tolerance, although the mechanisms for this were not understood and indeed are still being elucidated today [8].

Until the late 20th century, little was understood about the mode of action of the nitrate drugs beyond the fact that they appeared to cause vasodilatation through vascular smooth muscle relaxation. However, in 1977 the pharmacologist Ferid Murad and colleagues [9] showed that nitrate application caused stimulation of soluble guanylyl cyclase derived from rat liver and bovine tracheal smooth muscle. In turn, this caused an increase in the second messenger cGMP levels, which caused vascular relaxation. They suggested that the cGMP activation may occur via NO because they had also found that $\mathrm{NO}$ itself increased guanylyl cyclase activity $[9,10]$. Another group, the pharmacologist Robert Furchgott and his colleagues [11,12] showed that removal of endothelium from the blood vessels prevented the usual vasorelaxation caused by acetylcholine. This supported the importance of the vascular endothelium in vasorelaxation. Those investigators also showed that soluble guanylate cyclase could be activated by NO [12] and agreed with Murad's theory that NO could be the mediator of the action of nitrovasodilators on vascular smooth muscle. Furchgott and coworkers [13] also identified a vascular relaxant factor, which they called endothelial-derived relaxing factor, and which they thought might mediate the vascular relaxation in response to substances such as bradykinin, histamine, ATP, and ADP.

In 1986 it was first proposed that endothelial-derived relaxing factor and NO were the same molecule, and this was proven the following year in series of experiments reported by Ignarro [14] and Moncada [15] and their colleagues. Although most evidence points to $\mathrm{NO}$ release as being the mechanism of vasodilatation caused by nitrates, data showing a discrepancy between GTN-dependent vasodilatation and NO formation have called this concept into question [16].

\section{Mode of action of nitric oxide}

It is now known that NO activates guanylyl cyclase in vascular smooth muscle, leading to increased production of cGMP. This activates a cGMP-dependent protein kinase and leads to phosphorylation of proteins that are involved in the regulation of intracellular calcium levels. There is a resultant reduction in cytosolic calcium levels, and this leads to relaxation of vascular smooth muscle and hence vasodilatation. In addition to its vascular effects, NO also has inhibitory effects on platelet aggregation and effects on inflammation and pain perception. Endogenous $\mathrm{NO}$ is produced by nitric oxide synthase (NOS) from the substrate L-arginine (Figure 1). Different isoforms of NOS exist, including constitutive forms that provide continuous low-level production of $\mathrm{NO}$ and an inducible form, the expression of which increases upon stimulation by cytokines or other activators, leading to the production of large amounts of NO. The types of NOS are classified as endothelial NOS (eNOS; NOS3), which regulates vascular function; inducible NOS (iNOS; NOS2), which is present in vasculature but is also involved in immune responses; and neuronal NOS (nNOS; NOS1), which is present predominantly in the peripheral and central nervous systems. eNOS and nNOS are the constitutive forms of NOS.

One example of a condition in which lack of $\mathrm{NO}$ plays an important role is primary pulmonary hypertension [17]. This disease is thought to be due to an imbalance between vasodilating and vasoconstricting substances, and reduced NO bioavailability in the pulmonary circulation has been identified. Similarly, lack of NO is involved in the pathogenesis of pulmonary hypertension secondary to sickle cell disease. Hemolysis causes the release of hemoglobin from erythrocytes, and this free hemoglobin binds with $\mathrm{NO}$, reducing $\mathrm{NO}$ bioavailability and resulting in the formation of reactive oxygen species, which are potentially damaging to the pulmonary vasculature. In addition, arginase is released from the damaged erythrocytes, reducing the availability of arginine, which is the substrate for NO production by NOS [18]. Although drugs that cause cGMP activation, such as phosphodiesterase-5 inhibitors, or therapy with NO itself or NO-releasing drugs have had some beneficial effects in the management of pulmonary hypertension, the therapeutic benefits of arginine for pulmonary hypertension remain controversial $[19,20]$. 
Figure 1

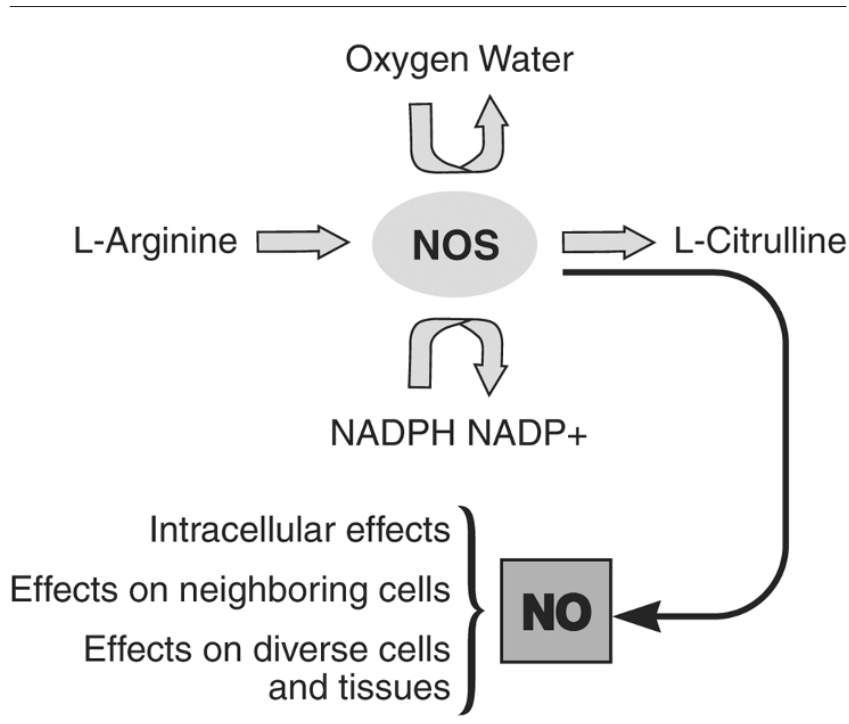

Production of nitric oxide. NADPH, nicotinamide adenine dinucleotide phosphate; NO, nitric oxide; NOS, nitric oxide synthase.

\section{Osteoarthritis and nitric oxide Mechanisms of osteoarthritis}

The clinical manifestations of osteoarthritis stem mostly from the changes that occur within articular cartilage. Cartilage structure consists of chondrocytes surrounded by an extracellular matrix of macromolecules, notably proteoglycans (particularly glycosaminoglycans) and collagen. Glycosaminoglycans are responsible for the high water binding capacity of cartilage, a physical property that is essential to making cartilage resistant to compression, durable to shock loads and smooth-surfaced in health. Initiating factors in the degeneration of cartilage - the primary finding in osteoarthritis are still not fully understood. Abnormal load on normal cartilage or normal load on abnormal cartilage may account for the degeneration, but they do not describe the details and neither do they address the variation in presentation of osteoarthritis, even within individuals. In early osteoarthritis there is evidence for increased synthetic activity of chondrocytes. Progression of osteoarthritis is accompanied by decreased proteoglycans and collagen synthesis, disrupting the mechanical strength of cartilage. Erosion reduces joint space and subchondral bone becomes more vascular and cellular, particularly at points of greater mechanical stress.

\section{Inflammation and osteoarthritis}

The absence of systemic features of inflammation or local findings such as the presence of neutrophils within synovial fluid have traditionally prevented osteoarthritis being considered within the inflammatory arthropathies. However, joints acutely affected by osteoarthritis may exhibit all of the clinical signs of inflammation [21]. Therapies that reduce the inflammatory response, such as NSAIDs and intra-articular steroid, provide symptomatic relief in osteoarthritis. Chondrocytes, which are the cellular occupants of cartilage and therefore are central to maintaining the integrity of the matrix, may produce inflammatory mediators (including cytokines) under conditions of stress. Such cytokines, including IL-1 and tumor necrosis factor- $\alpha$, stimulate the production of prostaglandins and NO. The complex interplay between these mediators and the microenvironment of the cartilage matrix may direct chondrocytes toward catabolism or anabolism [22].

These and other observations indicate that osteoarthritis is at least partly an inflammatory process. However, diseasemodifying osteoarthritis drugs have thus far been an elusive goal of research in osteoarthritis. The success of biologic therapies such as tumor necrosis factor- $\alpha$ antagonists in rheumatoid arthritis has stimulated hope that targeting cytokine modulators may also be useful in osteoarthritis. Progress in this area will be dependent on many other issues. One is a better understanding of how the inflammatory activity in osteoarthritis fits in with other recognized risk factors such as increasing age, obesity, previous joint damage and genetics. Another is how to achieve acceptable risk/benefit ratios from the treatments with respect to their safety and economics.

\section{Inducible nitric oxide synthase expression in arthritis}

Expression of iNOS has been identified in many human cell types, but chondrocytes were among the first to be recognized [23]. Many additional pieces of evidence link NO to the pathogenesis of osteoarthritis. Osteoarthritic joints exhibit elevated NO production as well as increased amounts of other inflammatory mediators. Patients with osteoarthritis (and rheumatoid arthritis) exhibit markers of enhanced NO production in their synovial fluid, serum, and urine, including increased levels of $\mathrm{NO}$, increased circulating nitrites and nitrates, and upregulation of iNOS expression in chondrocytes [24]. Most human cells that are capable of iNOS expression require multiple synergistically active cytokines to induce NO synthesis. Human chondrocytes, however, differ significantly and may be induced by a single cytokine such as IL-1 [25]. iNOS expression in osteoarthritis occurs mainly in chondrocytes, whereas in rheumatoid arthritis it occurs predominantly in synovial lining cells, endothelial cells, chondrocytes, infiltrating mononuclear cells, and synovial fibroblasts $[25,26]$. Constitutive isoforms of NO synthase are also observed in synovial lining and vascular smooth muscle from osteoarthritic joints [27].

\section{Effects of nitric oxide in joints}

Much of the in vitro work on the effects of NO has been carried out in environments with normal oxygen tension, whereas cartilage is an avascular tissue with low oxygen tension. Caution may therefore be needed in extrapolating the results in vivo. Within the context of osteoarthritis, NO appears mostly to be a proinflammatory and destructive mediator. However, NO is also a mediator of normal physiological responses in the body and is produced by chondro- 
cytes from normal cartilage. Therefore, NO generated by constitutive NOS enzymes may have beneficial effects such as improved blood flow through vasodilatation, but under different circumstances, at higher concentrations produced by iNOS, NO may enhance chondrocyte death and suppress the synthesis of the cartilaginous matrix. One important factor may be the NO concentration within the microenvironment of the cartilage. Constitutive NOS enzymes generate $\mathrm{NO}$ at the picomolar level, whereas iNOS is several orders of magnitude more active. At higher concentrations the effects of $\mathrm{NO}$ are mediated through reactive oxygen species, which modulate protein activity through $S$-nitrosylation of their cysteine residues. Proteins thus affected include transcription factors, transforming growth factor- $\beta$, insulin-like growth factor-I, signaling kinases, ion channels, and matrix metalloproteinases. Higher NO concentrations also lead to the formation of peroxynitrite, a reactive mediator formed by the reaction of superoxide with $\mathrm{NO}$, which may have diverse negative effects on protein and cell function [28]. NO may therefore have a mixture of positive and negative effects in relation to inflammation in osteoarthritic joints.

\section{Joint pain and nitric oxide}

Joint pain is the main symptom of osteoarthritis, and relief of pain is the mainstay of current therapies. Pain fibers are present throughout all parts of synovial joints except articular cartilage, although in advanced osteoarthritis the articular cartilage becomes partially innervated and vascularized. The earliest pathological changes in osteoarthritic joints are probably subclinical [29], but there is also much variability in the symptoms associated with more advanced changes in arthritic joints between patients, in different joints in the same patient, and in individual joints over time.

The role of $\mathrm{NO}$ in pain is complex because it is thought to have both positive and negative effects on pain perception. Low level production of NO by the constitutive forms of NOS may relieve pain by increasing vasodilatation and improving circulation as well as by reducing nerve irritation and inflammation per se. There is some evidence that this pathway of NO production is disrupted in abnormally loaded joints [30]. Conversely, increased NO production after activation of iNOS by inflammatory cytokines can increase pain perception. In rat models, it has been shown that it is possible to reduce pain in a vascular pain model by infusing $N^{G}$-nitro-L-arginine methyl ester (L-NAME), an inhibitor of NOS, and to restore the pain by infusing the NO donor sodium nitroprusside, suggesting that the pain is mediated by NO [31]. Similarly, in another study [32] infusion of L-NAME prevented hyperalgesia induced by peroxynitrite.

In osteoarthritic joints, NO could conceivably reduce pain by several different mechanisms [33]. Improved blood flow secondary to vasodilatation may restore oxygen, growth factors, and nutrients to the synovium and subchondral bone. Nerve ischemia, leading to abnormal nerve membrane potential and conduction, is also improved by vasodilatation. Through the cGMP pathway, NO opens potassium channels and reduces calcium influx from calcium channels. Consequent hyperpolarization of the nerve-cell membrane blocks pain transmission. Further studies in humans are needed if we are to understand better the therapeutic possibilities of $\mathrm{NO}$ donation in the management of joint pain.

\section{Nonsteroidal anti-inflammatory drugs and osteoarthritis}

NSAIDs work by blocking prostaglandin synthesis, largely by inhibiting the cyclo-oxygenase (COX) enzymes, which catalyze the conversion of arachidonic acid to prostaglandins and thromboxane. COX inhibition has anti-inflammatory, analgesic, and antipyretic effects. There are two main isoforms of the COX enzyme: COX-1 and COX-2. The former is constitutively expressed in most body cells and is thought to have homeostatic functions in tissue maintenance, whereas COX-2 is inducible, being activated by cytokines released from inflammatory cells, such as tumor necrosis factor- $\alpha$ and IL-1, and leads to the production of inflammatory mediator prostaglandins. Most of the desired effects of NSAIDs (for example, their anti-inflammatory effects) therefore occur via COX-2 inhibition, whereas the unwanted adverse effects such as gastrointestinal damage largely occur via COX-1 inhibition, especially inhibition of production of the gastric mucosal protectant prostaglandins $\mathrm{PGl}_{2}$ and $\mathrm{PGE}_{2}$. The COX-2 selective inhibitors were designed to have similar anti-inflammatory and analgesic properties to the nonselective NSAIDs but with a lower incidence of gastrointestinal adverse effects such as bleeding and ulcer disease. Indeed, this has proved to be the case in metaanalyses of clinical trials of COX-2 selective inhibitors versus nonselective NSAIDs [34,35].

\section{Nonsteroidal anti-inflammatory drugs and cardiovascular risk}

When it was first noted that increased cardiovascular risk may be associated with rofecoxib, one proposed mechanism was that COX-2 inhibitors may cause an imbalance of prothrombotic and antithrombotic prostaglandins favoring thrombosis, because COX-2 inhibitors reduce production of prostacyclin by the endothelium, but they do not affect the COX-1 dependent production of thromboxane by platelets. However, more recent data suggest that although rofecoxib is probably associated with a greater risk for cardiovascular disease than other NSAIDs, the other COX-2 inhibitors probably have a similar risk to that of most of the traditional NSAIDs. Other mechanisms not specific to COX-2 inhibitors are therefore likely to be important. For example, a recent study showed that both COX-2 inhibitors and traditional NSAIDs upregulate vascular NADPH (nicotinamide adenine dinucleotide phosphate) oxidases and uncouple eNOS, leading to endothelial dysfunction [36]. Further clinical studies are ongoing to establish the extent of cardiovascular disease associated with both COX-2 inhibitors and traditional NSAIDs. 


\section{Atherosclerosis, vascular tone and blood pressure: roles of nitric oxide and cyclo-oxygenase-2}

Early atherosclerotic lesions are thought to be partly influenced by flow patterns and forces exerted on the vessel walls. In animal models, steady laminar shear stress induces the upregulation of both eNOS and COX-2 [37]. NO produced by the vascular endothelium is thought to have an important influence on vascular tone and hence blood pressure. Indeed, intravenous infusion of the NO synthase inhibitor $N G$-monomethyl-L-arginine (L-NMMA), increases blood pressure in human volunteers [38]. Strategies to donate NO may therefore help to lower blood pressure. One example of a drug in which this strategy has been employed is the $\beta$-blocker nebivolol. In addition to its $\beta_{1}$-receptor antagonist properties, nebivolol also activates eNOS and may stimulate the expression of eNOS, leading to increased NO production. Although nebivolol has effects on blood pressure similar to those of other $\beta$-blockers (for instance, atenolol [39]), it has different hemodynamic effects. For example, unlike atenolol, it causes vasodilatation in the human forearm when it is infused intra-arterially, and this effect can be blocked by the co-administration of L-NMMA, which suggests that it is NO dependent [40]. Nebivolol also improves endothelial function in hypertensive patients [41] and reduces arterial wave reflection, thus lowering central blood pressure more than atenolol $[42,43]$.

\section{Nonsteroidal anti-inflammatory drugs and blood pressure}

Even small differences in blood pressure can have major influences on outcome. It has been estimated that a $5 \mathrm{mmHg}$ lower usual diastolic blood pressure leads to about a $40 \%$ reduction in risk for stroke and a $25 \%$ reduction in risk for coronary heart disease $[44,45]$. NSAIDs have variable effects on blood pressure, but several of them appear to increase blood pressure, especially in previously hypertensive individuals. This effect is thought to occur via different mechanisms, including activation of the renin-angiotensin system, vasoconstriction due to inhibition of vasodilatory prostaglandins, sodium and water retention, and production of vasoconstricting factors including endothelin-1 and metabolites of arachidonic acid. NSAIDs also interact with antihypertensive medications, counteracting their antihypertensive effects [46].

In general, treatment with a NSAID or paracetamol tends to cause a small but significant increase in blood pressure. In one meta-analysis of largely hypertensive patients [47], indomethacin and naproxen were associated with the greatest increases in blood pressure, whereas ibuprofen, piroxicam, sulindac, and aspirin had negligible effects on blood pressure. However, in a recent randomized controlled trial [48], treatment with lumiracoxib led to significantly lower blood pressure than treatment with ibuprofen in patients with controlled hypertension.
Overall, both traditional NSAIDs and COX-2 selective NSAIDs appear to increase blood pressure, but there are variations between individual agents. In one meta-analysis [49], the increases in systolic/diastolic blood pressures versus placebo with traditional NSAIDs were $2.83 / 1.34 \mathrm{mmHg}$ and with coxibs (COX-2 selective inhibitors) they were 3.85/ $1.06 \mathrm{mmHg}$. However, much of the elevation in blood pressure associated with coxibs as a group in this analysis might have been attributable to the effects of rofecoxib. In a further study [50], rofecoxib caused increases in systolic and diastolic blood pressures compared with celecoxib. It was hypothesized that this may be due to competition between rofecoxib and aldosterone for metabolism by cytosol reductase; however, aldosterone levels were similar in both arms of the study. Interestingly, in patients with hypertension and osteoarthritis, patients taking $\beta$-blockers or angiotensinconverting enzyme inhibitors had a greater increase in blood pressure and a higher incidence of peripheral edema with rofecoxib than with celecoxib, but there were no significant differences in blood pressure with either coxib in patients taking calcium channel blockers or diuretics [51]. In another study [52], among elderly patients with essential hypertension and arthritis, indomethacin increased blood pressure in those taking enalapril but not in those taking amlodipine. However, in patients taking lisinopril for hypertension, celecoxib had no effect on 24-hour ambulatory blood pressure compared with placebo, with the placebo-corrected differences in 24-hour ambulatory blood pressure being 1.6/1.2 mmHg (nonsignificant) [53].

More data are needed on the effects of different NSAIDs on blood pressure and on relationships with pharmacodynamics, pharmacokinetics, and dosing regimens of the various NSAIDs and background antihypertensive therapies. Based on the data reported so far, it appears that chronic NSAID therapy can influence blood pressure significantly and that this may be relevant to cardiovascular event outcomes.

\section{The vascular endothelium and endothelial mediators}

The vascular endothelium is a complex structure that releases mediators with important paracrine and autocrine effects on vascular tone and blood pressure, platelet aggregation, thrombus formation, and atheroma development. NO is one of many mediators released by the endothelium; others include prostaglandins (for example, $\mathrm{PGI}_{2}$ and $\mathrm{PGH}_{2}$ ), endothelin-1, thromboxane $A_{2}$, interleukins, bradykinin, angiotensin II, chemokines, nuclear factor- $\kappa \mathrm{B}$, and vascular endothelial growth factor (Figure 2). These mediators interact to control aspects such as dilatation/constriction, proliferation, thrombosis, inflammation, permeability, and angiogenesis, all of which contribute to the health (or disease) of the vascular endothelium. NO availability has long been used to define endothelial function and a reduction in NO bioavailability is generally classed as 'endothelial dysfunction' although in practice, alterations in other mediators may also be involved in this state. 


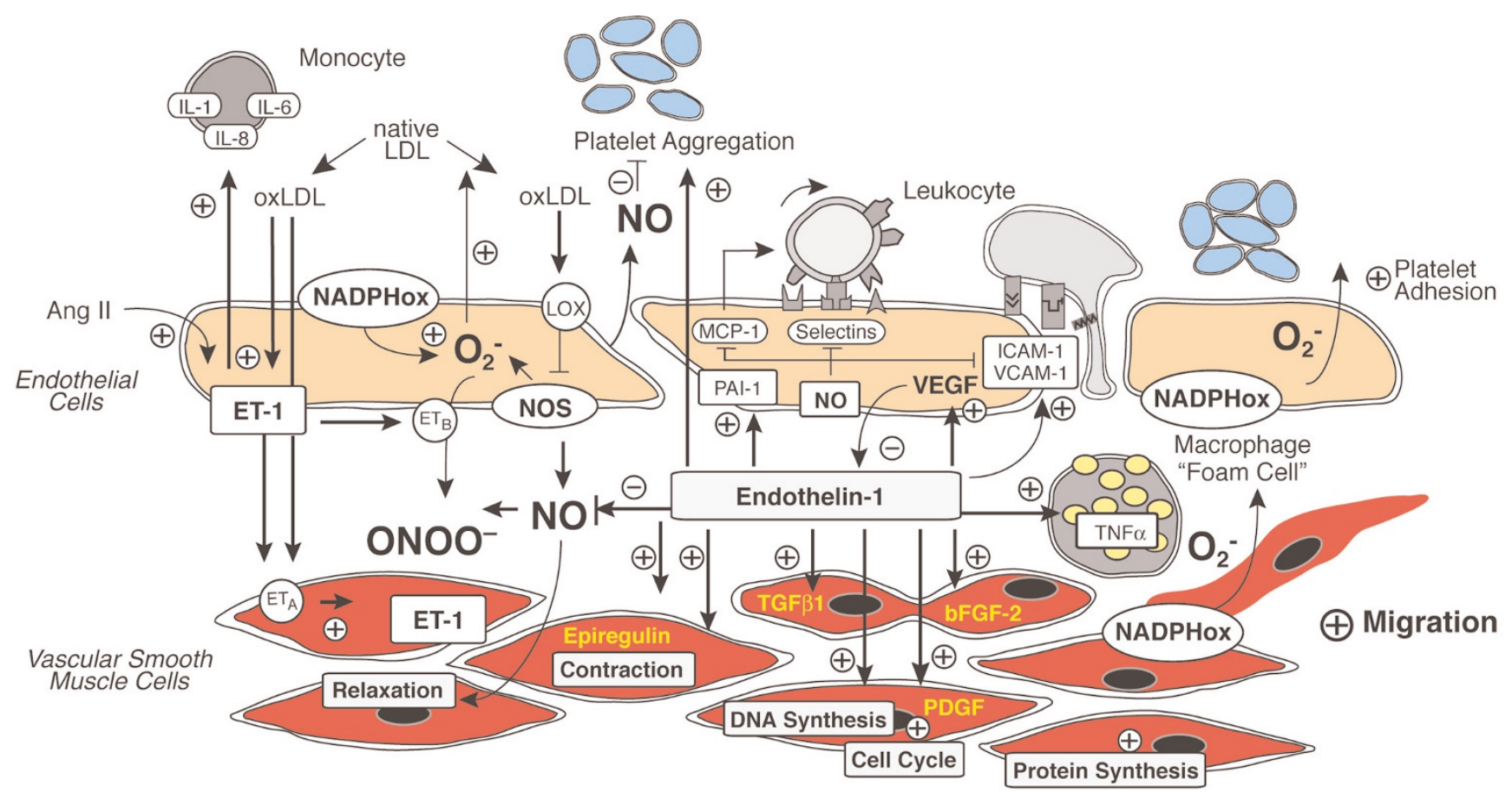

$\oplus$ Proliferation

Vascular endothelial mediators and their effects. Adapted with permission from Lüscher and Barton [115]. Ang, angiotensin; bFGF, basic fibroblast growth factor; $\mathrm{ET}$, endothelin; $\mathrm{ET}_{\mathrm{A} / \mathrm{B}}$, endothelin receptor subtype A/B; ICAM, intracytoplasmic adhesion molecule; IL, interleukin; LDL, low-density

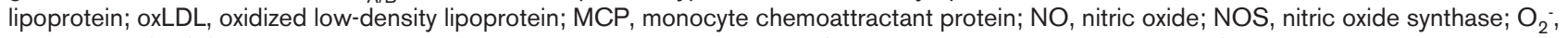
superoxide; ONOO; peroxynitrite; PAl, plasminogen activator inhibitor; PDGF, platelet derived growth factor; TGF, transforming growth factor; TNF, tumor necrosis factor; VCAM, vascular cell adhesion molecule.

\section{Endothelial dysfunction}

Endothelial dysfunction is present in many disease states, including diabetes mellitus [54], hyperlipidemia [55], and hypertension [56], as well as in cigarette smoking [57] and increasing age [58]. Interestingly, most of these conditions are considered to be risk factors for cardiovascular disease in their own right, and many of them tend to cluster together in the same individuals. Indeed, endothelial dysfunction is a good surrogate marker or predictor of cardiovascular risk [59-61] and it is considered by some to be the earliest detectable sign of atherosclerosis [62,63]. More recently, endothelial dysfunction has also been identified in inflammatory arthritides, including rheumatoid arthritis [64-66], systemic lupus erythematosus [67,68], psoriatic arthritis [69], and ankylosing spondylitis [70]. In psoriatic arthritis, the degree of endothelial dysfunction has been shown to correlate with disease activity, as assessed using C-reactive protein (CRP) level and erythrocyte sedimentation rate [69]. In an anterior-cruciate ligament deficient rabbit knee model of osteoarthritis, there was reduced vascular responsiveness to acetylcholine in the medial collateral ligament vessels compared with controls, suggesting that a degree of endothelial dysfunction may also exist in osteoarthritis [71], although there is little evidence of this in humans to date.

Several different cardiovascular agents have been shown to improve endothelial function; interestingly, many of these have also improved survival or reduced future cardiovascular events in large outcome trials. For example, statins improve endothelial function [72] and reduce mortality [73]. Also, spironolactone improves endothelial function [74] and reduces mortality in patients with heart failure [75]. Other examples include aspirin [76] and angiotensin converting enzyme inhibitors [77]. In most cardiovascular studies nitrates have not affected survival outcomes, but there are exceptions. When combined, isosorbide dinitrate and hydralazine therapy given to African-Americans with heart failure improved survival significantly compared with placebo [78]. Hydralazine has antioxidant effects in addition to its blood pressure lowering effects [79], and it has been suggested that this may partly account for the favorable outcome in the above study. However, it is also of note that a meta-analysis [80] showed that long-term organic nitrate use in patients after myocardial infarction was associated with higher mortality. 
Therefore, it is not possible at present to generalize about whether NO donors and drugs improving endothelial function will always improve outcome, because further investigation of the effects of individual agents is required.

\section{Measurement of endothelial function}

There are many ways to measure endothelial function. The 'gold standard' method employs venous occlusion plethysmography to measure forearm blood flow responses to intrabrachial arterial infusions of the endothelium-dependent vasodilator acetylcholine [81]. Usually, the NO-releasing endothelium-independent vasodilator sodium nitroprusside is infused as a control, and baseline production of NO by the endothelium can also be assessed by measuring the reduction in forearm blood flow after infusion of the NOS inhibitor L-NMMA. Endothelial function can also be measured in the coronary arteries, for example during coronary angiography, again by assessing vascular responses to infusion of acetylcholine. Other less invasive methods of assessing endothelial function include flow-mediated dilatation $[82,83]$, which involves measuring flow responses to brief cuff occlusion of the brachial artery using ultrasonography, and using pulse wave analysis to measure responses to the endothelium-dependent vasodilator salbutamol in comparison with the endothelium-independent vasodilator GTN [84]. Plasma or serum markers of endothelial function, including $\mathrm{N}$ acetyl- $\beta$-glucosaminidase, E-selectin, P-selectin, and intracytoplasmic adhesion molecule-1, and the presence of circulating endothelial progenitor cells have also been used to assess endothelial activity.

\section{Nonsteroidal anti-inflammatory drugs and endothelial function}

In several studies it has been shown that aspirin improves endothelial function in humans $[76,85,86]$, and this is one of the mechanisms that has been proposed for its cardiovascular protective effect. However, data regarding the effects of other NSAIDs on endothelial function are less clear. In one study, diclofenac infusion increased methacholineinduced vasodilatation measured by venous occlusion plethysmography only in those with chronic renal failure, but not in healthy volunteers [87]. In patients with rheumatoid arthritis, neither indomethacin nor rofecoxib improved flowmediated dilatation [88].

Likewise, 8 weeks of rofecoxib therapy in patients with coronary artery disease had no influence on flow-mediated dilatation or inflammatory markers [89], but in two other studies short-term [90] or 6 months of therapy [91] with rofecoxib led to reductions in CRP and IL- 6 levels but no changes in brachial artery flow-mediated dilatation. In another study [92], no change in acetylcholine-induced forearm blood flow response was seen after treatment with either rofecoxib or naproxen in healthy volunteers. Hence, many of the data have suggested little effect of these drugs on endothelial function.
Interestingly, however, parecoxib (prodrug of valdecoxib) reduced endothelium-dependent vasodilatation in response to acetylcholine (measured using venous occlusion plethysmography) in patients with essential hypertension [93]. Conversely, in a cross-over study of male patients with severe coronary artery disease, 2 weeks of celecoxib therapy resulted in greater brachial artery flow-mediated (endothelium-dependent) dilatation compared with placebo. Celecoxib therapy also reduced high-sensitivity CRP and oxidized low-density lipoprotein levels [94], suggesting that it had a positive effect on reducing inflammation and oxidative stress, although whether this was the mechanism for the improvement in endothelial function is not clear. Celecoxib has also been found to improve flow-mediated dilatation in patients with essential hypertension both acutely and after 1 week of therapy [95]. Whether differing effects of NSAIDs on endothelial function are directly relevant to the overall cardiovascular risks attributable to each agent remains to be determined [61].

\section{Nonsteroidal anti-inflammatory drugs and platelet function}

Aspirin inhibits platelet aggregation by binding irreversibly to platelet COX-1, inhibiting the production of platelet thromboxane for the life of the platelet. Other nonselective NSAIDs bind reversibly to COX-1 and have variable degrees of antiplatelet aggregatory effects, depending on the degree of COX-1 inhibition and the affinity of binding. In addition, some NSAIDs appear to interfere with the ability of aspirin to bind to platelet COX-1 and may therefore inhibit the antiplatelet effects of aspirin in patients taking both together. This may even negate the influence of low-dose aspirin in cardiovascular disease prevention. In a recent study measuring ex vivo platelet function in healthy volunteers [96], ibuprofen, naproxen, indomethacin, and tiaprofenic acid were found to reduce the effect of aspirin on platelets. No apparent interaction with platelet function was observed between celecoxib or sulindac and aspirin. Studies have also suggested a link between co-administration of ibuprofen and aspirin and reduced cardiovascular disease prevention with aspirin $[97,98]$. NO inhibits platelet aggregation via a cGMPdependent mechanism, and therefore the co-administration of NO with NSAIDs could be beneficial in some circumstances in which inhibition of platelet aggregation is also a goal in a patient who requires NSAID therapy.

\section{Cyclo-oxygenase inhibiting nitric oxide donating drugs}

Over the past few years, 'NO-releasing' NSAIDs have been developed; in these agents, an NSAID is chemically linked with a NO moiety [99]. Originally, these were designed to improve the gastrointestinal side-effect profiles of the NSAIDs; in particular, it was hoped that they would reduce ulcer disease and gastrointestinal hemorrhage. However, as more evidence accumulates about the possible adverse cardiovascular effects of many of the NSAIDs, the question of 
whether the addition of the NO moiety to a NSAID might improve the cardiovascular risk profile of patients taking chronic NSAIDs has arisen. NO is released slowly from the CINOD, and this is thought to take place in vivo via an enzymatic esterase based reaction [100]. Various CINODs have been developed, including NO derivatives of aspirin, flurbiprofen, naproxen (naproxcinod), diclofenac, and ibuprofen. Few data are currently available on their effects in humans.

CINODs have extra effects over and above those of their parent NSAID. For example, NO-aspirin, unlike standard aspirin, reduces levels of the proinflammatory cytokine IL-1 $\beta$ by inhibiting gastric caspase-1 activity [101]. In various animal models of acute and chronic inflammation, CINODs have exhibited similar or even greater effects on inhibition of inflammation to those of their parent NSAIDs [102,103]. Also, a NO-releasing aspirin derivative had a sevenfold more potent effect on inhibition of platelet aggregation than aspirin when given to rats [104].

Data on the vascular effects of CINODs show that there is some influence on vascular tone. In vitro, the CINODs NOflurbiprofen and NO-aspirin, and a NO-steroidal compound, NO-prednisolone, all cause vasorelaxation of rat aortic rings via a NO-dependent mechanism, with a vasodilator potency at least three orders of magnitude less than that of sodium nitroprusside [105]. However, there were no effects on systemic blood pressure when NO-flurbiprofen or NO-aspirin were given intravenously to anesthetized rats. When naproxen or naproxcinod was administered to rats for 4 weeks, the naproxen treated rats had significantly higher blood pressure than did those treated with naproxcinod or placebo. In a group of rats pretreated with the NOS inhibitor L-NAME to induce hypertension, naproxcinod reduced the blood pressure significantly whereas naproxen alone increased the blood pressure [106].

The effects of naproxcinod on blood pressure in humans have been investigated in clinical studies. A 6-week clinical phase 2 study conducted in osteoarthritis patients comparing naproxcinod versus rofecoxib and naproxen [107] showed trends toward reductions in mean systolic and diastolic blood pressures with naproxcinod $375 \mathrm{mg}$ and $750 \mathrm{mg}$ twice daily, as compared with trends towards increased blood pressure in the rofecoxib and naproxen $500 \mathrm{mg}$ groups. The first phase 3 study with naproxcinod in patients with osteoarthritis [108] identified small reductions from baseline in mean office systolic blood pressure with naproxcinod $750 \mathrm{mg}$ twice daily and in mean office diastolic blood pressure with naproxcinod $375 \mathrm{mg}$ twice daily or $750 \mathrm{mg}$ twice daily, as compared with naproxen $500 \mathrm{mg}$ twice daily. In an exploratory 24-hour ambulatory blood pressure monitoring study performed in hypertensive patients [109], differential effects on blood pressure of naproxcinod compared with naproxen were also observed. Although the primary end-point of least square mean change from baseline in average 24-hour systolic blood pressure $(1.9 \mathrm{mmHg})$ was not statistically significantly different, there was a reduction in the secondary end-point of average 24-hour diastolic blood pressure of $1.9 \mathrm{mmHg}$ $(P=0.007)$ in favor of naproxcinod.

Some of the human data presented thus far reveal nonsignificant trends rather than actual differences in blood pressure. However, even small reductions in blood pressure may have significant effects on cardiovascular outcome within the context of chronic therapy with NSAIDs, because it has been reported that use of many of these agents (including naproxen, meloxicam, diclofenac, and ibuprofen) results in average increases in mean arterial pressure as high as $5.5 \mathrm{mmHg}$ [47,110-112]. Further data are required to evaluate whether there is a true benefit of CINODs on blood pressure in humans, and such studies are currently ongoing. The effects of CINODs on endothelial function are not yet known. Also, it is unclear whether CINODs might be subject to the development of vascular tolerance in a similar way to that seen with organic nitrates.

There is also some evidence that CINODs protect the myocardium from ischemia/reperfusion injury. Using left ventricular end-diastolic pressure as a surrogate marker for myocardial dysfunction in an in vitro perfused rabbit heart model [113], pretreatment with aspirin, celecoxib, or meloxicam increased myocardial damage after ischemic insult and reperfusion. However, pretreatment with NCX-4016 (an NOreleasing aspirin derivative) had the opposite effect, reducing myocardial damage and dysfunction caused by the insult. In a similar study [114], in dose-related manners, naproxen increased ischemia/reperfusion injury compared with vehicle whereas naproxcinod reduced ischemia/ reperfusion injury.

It is potentially the case that some of the cardiovascular risk associated with chronic NSAID use may be ameliorated by steady donation of NO in the vasculature. However, further work in humans is necessary to investigate this potential.

\section{Conclusions}

Osteoarthritis is a common and disabling disease that is becoming more prevalent as our population ages. Partly as a result of its association with increased age, many patients being treated for osteoarthritis will also have risk factors for cardiovascular disease. Therefore, the remit of future treatment strategies for osteoarthritis must broaden from simply managing joint pain to take into account the overall management of the patient as well, along with any co-existing risk factors. We must also carefully consider the risks for gastrointestinal, cardiovascular, and other adverse effects of all drug therapies. Both traditional NSAIDs and COX-2 selective NSAIDs have been associated with increased cardiovascular risk, but many patients with osteoarthritis rely on these medications to achieve adequate symptomatic 
control; therefore, any measures that might counteract the cardiovascular risks associated with NSAIDs would be welcome.

$\mathrm{NO}$ is a key regulator of vascular function in health and disease with effects on vascular tone, platelet function, and endothelial function. The donation of extra NO by pharmaceutical agents is a possible means of influencing vascular function and cardiovascular outcomes. The recently developed CINODs represent an exciting new class of agent that show promise in the pharmacological management of the pain associated with osteoarthritis, being at least as effective as NSAIDs in animal studies to date. They have also shown some potential for being more effective, given the effects of $\mathrm{NO}$ on pain perception, while also offering additional benefits such as increased gastric protection. This may improve pain control in osteoarthritis. At the same time, previous data have suggested that some of the joint damage in osteoarthritis has been mediated by $\mathrm{NO}$; this therefore requires further investigation in humans. However, turning once again to the broader cardiovascular perspective, there may be some overall advantages of these compounds in the management of osteoarthritis. Theoretically, CINODs may influence endothelial function, vascular tone, and other surrogate markers of cardiovascular risk. If this were shown to reduce the incidence of cardiovascular events in patients taking chronic NSAID therapy, then this would be a major breakthrough in the management of arthritis in general. Further studies to investigate the effects of CINODs on blood pressure, vascular function, and structure will guide their future use in humans.

\section{Competing interests}

This article is based on an invited talk given at the European League Against Rheumatism symposium 2008 by TMM, for which he was paid an honorarium by NicOx. TMM has received speaker's fees, support for travel costs, consulting fees, and research funding from several other pharmaceutical companies during the past 5 years. ISM and DR have no competing interests.

\section{Acknowledgements}

This article is published as part of Arthritis Research \& Therapy Volume 10 Supplement 2, 2008: New insights in the role of nitric oxide in the management of osteoarthritis. The full contents of the supplement are available online at http://arthritis-research.com/supplements/10/S2.

Publication of the supplement has been supported by an unrestricted educational grant from NicOx.

\section{References}

1. National Collaborating Centre for Chronic Conditions: Osteoarthritis: National Clinical Guidelines for Care and Management in Adults. London, UK: Royal College of Physicians; 2008.

2. Bresalier RS, Sandler RS, Quan H, Bolognese JA, Oxenius B, Horgan K, Lines C, Riddell R, Morton D, Lanas A, Konstam MA, Baron JA; Adenomatous Polyp Prevention on Vioxx (APPROVe) Trial Investigators: Cardiovascular events associated with rofecoxib in a colorectal adenoma chemoprevention trial. $N$ Engl $J$ Med 2005, 352:1092-1102.
3. Mukherjee D, Nissen SE, Topol EJ: Risk of cardiovascular events associated with selective COX-2 inhibitors. JAMA 2001, 286:954-959.

4. Cannon CP, Curtis SP, FitzGerald GA, Krum H, Kaur A, Bolognese JA, Reicin AS, Bombardier C, Weinblatt ME, van der Heijde D, Erdmann E, Laine L; MEDAL Steering Committee: Cardiovascular outcomes with etoricoxib and diclofenac in patients with osteoarthritis and rheumatoid arthritis in the Multinational Etoricoxib and Diclofenac Arthritis Long-term (MEDAL) programme: a randomised comparison. Lancet 2006, 368:17711781.

5. Farooq M, Haq I, Qureshi AS: Cardiovascular risks of COX inhibition: current perspectives. Expert Opin Pharmacother 2008, 9:1311-1319.

6. Marsh N, Marsh A: A short history of nitroglycerine and nitric oxide in pharmacology and physiology. Clin Exp Pharmacol Physiol 2000, 27:313-319.

7. Murrell W: Nitroglycerine as a remedy for angina pectoris. Lancet 1879, 80:80-81.

8. Daiber A, Wenzel $P$, Oelze $M$, Munzel $T$ : New insights into bioactivation of organic nitrates, nitrate tolerance and crosstolerance. Clin Res Cardiol 2008, 97:12-20.

9. Katsuki S, Arnold W, Mittal C, Murad F: Stimulation of guanylate cyclase by sodium nitroprusside, nitroglycerin and nitric oxide in various tissue preparations and comparison to the effects of sodium azide and hydroxylamine. J Cyclic Nucleotide Res 1977, 3:23-35.

10. Murad F, Arnold WP, Mittal CK, Braughler JM: Properties and regulation of guanylate cyclase and some proposed functions for cyclic GMP. Adv Cyclic Nucleotide Res 1979, 11:175-204.

11. Furchgott RF, Zawadzki JV: The obligatory role of endothelial cells in the relaxation of arterial smooth muscle by acetylcholine. Nature 1980, 288:373-376.

12. Furchgott RF, Zawadzki JV, Cherry PD: Role of endothelium in the vasodilator response to acetylcholine. In Vasodilatation. Edited by Vanhoutte PM, Leusen I. New York, NY: Raven Press; 1981:49-66

13. Cherry PD, Furchgott RF, Zawadzki JV, Jothianandan D: Role of endothelial cells in relaxation of isolated arteries by bradykinin. Proc Natl Acad Sci USA 1982, 79:2106-2110.

14. Ignarro LJ, Byrns RE, Buga GM, Wood KS: Endothelium-derived relaxing factor from pulmonary artery and vein possesses pharmacologic and chemical properties identical to those of nitric oxide radical. Circ Res 1987, 61:866-879.

15. Palmer RM, Ferrige AG, Moncada S: Nitric oxide release accounts for the biological activity of endothelium-derived relaxing factor. Nature 1987, 327:524-526.

16. Kleschyov AL, Oelze M, Daiber A, Huang Y, Mollnau H, Schulz E, Sydow K, Fichtlscherer B, Mülsch A, Münzel T: Does nitric oxide mediate the vasodilator activity of nitroglycerin? Circ Res 2003, 93:e104-e112.

17. Chin KM, Rubin LJ: Pulmonary arterial hypertension. J Am Coll Cardiol 2008, 51:1527-1538.

18. Vichinsky EP: Pulmonary hypertension in sickle cell disease. $N$ Engl J Med 2004, 350:857-859.

19. Morris CR: New strategies for the treatment of pulmonary hypertension in sickle cell disease: the rationale for arginine therapy. Treat Respir Med 2006, 5:31-45.

20. Boger RH, Mugge A, Bode-Boger SM, Heinzel D, Hoper MM, Frolich JC: Differential systemic and pulmonary hemodynamic effects of L-arginine in patients with coronary artery disease or primary pulmonary hypertension. Int J Clin Pharmacol Ther 1996, 34:323-328.

21. Goldring MB, Goldring SR: Osteoarthritis. J Cell Physio/ 2007, 213:626-634.

22. Goldring MB, Berenbaum F: The regulation of chondrocyte function by proinflammatory mediators: prostaglandins and nitric oxide. Clin Orthop Relat Res 2004, Suppl:S37-S46.

23. Charles IG, Palmer RM, Hickery MS, Bayliss MT, Chubb AP, Hall VS, Moss DW, Moncada S: Cloning, characterization, and expression of a cDNA encoding an inducible nitric oxide synthase from the human chondrocyte. Proc Natl Acad Sci USA 1993, 90:11419-11423.

24. Wahl SM, Cartney-Francis N, Chan J, Dionne R, Ta L, Orenstein $\mathrm{JM}$ : Nitric oxide in experimental joint inflammation. Benefit or detriment? Cells Tissues Organs 2003, 174:26-33.

25. Vuolteenaho K, Moilanen T, Knowles RG, Moilanen E: The role of 
nitric oxide in osteoarthritis. Scand J Rheumato/ 2007, 36:247258.

26. Grabowski PS, Wright PK, Van 't Hof RJ, Helfrich $\mathrm{MH}$, Ohshima $\mathrm{H}$, Ralston SH: Immunolocalization of inducible nitric oxide synthase in synovium and cartilage in rheumatoid arthritis and osteoarthritis. Br J Rheumatol 1997, 36:651-655.

27. Di Mauro D, Bitto L, D'Andrea L, Favaloro A, Giacobbe O, Magaudda L, Rizzo G, Trimarchi F: Behaviour of nitric oxide synthase isoforms in inflammatory human joint diseases: an immunohistochemical study. Ital J Anat Embryol 2006, 111:111-123.

28. Szabo C, Ischiropoulos H, Radi R: Peroxynitrite: biochemistry, pathophysiology and development of therapeutics. Nat Rev Drug Discov 2007, 6:662-680.

29. Bonnet CS, Walsh DA: Osteoarthritis, angiogenesis and inflammation. Rheumatology (Oxford) 2005, 44:7-16.

30. Hancock CM, Riegger-Krugh C: Modulation of pain in osteoarthritis: the role of nitric oxide. Clin J Pain 2008, 24:353-365.

31. Masumi S, Senba E: Nitric oxide involvement in lipid emulsioninduced vascular pain in anesthetized rats. Eur J Pharmacol 2008 [Epub ahead of print].

32. Ndengele MM, Cuzzocrea S, Esposito E, Mazzon E, Di Paola R, Matuschak GM, Salvemini D: Cyclooxygenases 1 and 2 contribute to peroxynitrite-mediated inflammatory pain hypersensitivity. FASEB J 2008 [Epub ahead of print].

33. Hancock CM, Riegger-Krugh C: Modulation of pain in osteoarthritis: the role of nitric oxide. Clin J Pain 2008, 24:353-365.

34. Rostom A, Muir K, Dube C, Jolicoeur E, Boucher M, Joyce J, Tugwell P, Wells GW: Gastrointestinal safety of cyclooxygenase-2 inhibitors: a Cochrane Collaboration systematic review. Clin Gastroenterol Hepatol 2007, 5:818-828, 828 e811-815; quiz 768.

35. Hawkey CJ, Gitton X, Hoexter G, Richard D, Weinstein WM: Gastrointestinal tolerability of lumiracoxib in patients with osteoarthritis and rheumatoid arthritis. Clin Gastroenterol Hepato/ 2006, 4:57-66.

36. Li H, Hortmann M, Daiber A, Oelze M, Ostad MA, Schwarz PM, Xu H, Xia N, Kleschyov AL, Mang C, Warnholtz A, Münzel T, Förstermann U: COX2-selective and non-selective NSAIDs induce oxidative stress by upregulating vascular NADPH oxidases. J Pharmacol Exp Ther 2008, 326:745-753.

37. Topper JN, Cai J, Falb D, Gimbrone MA Jr: Identification of vascular endothelial genes differentially responsive to fluid mechanical stimuli: cyclooxygenase-2, manganese superoxide dismutase, and endothelial cell nitric oxide synthase are selectively up-regulated by steady laminar shear stress. Proc Natl Acad Sci USA 1996, 93:10417-10422.

38. Haynes WG, Noon JP, Walker BR, Webb DJ: Inhibition of nitric oxide synthesis increases blood pressure in healthy humans. $J$ Hypertens 1993, 11:1375-1380.

39. Van Nueten L, Taylor FR, Robertson Jl: Nebivolol vs atenolol and placebo in essential hypertension: a double-blind randomised trial. J Hum Hypertens 1998, 12:135-140.

40. Cockcroft JR, Chowienczyk PJ, Brett SE, Chen CP, Dupont AG, Van Nueten L, Wooding SJ, Ritter JM: Nebivolol vasodilates human forearm vasculature: evidence for an L-arginine/NOdependent mechanism. J Pharmacol Exp Ther 1995, 274:10671071.

41. Tzemos N, Lim PO, MacDonald TM: Nebivolol reverses endothelial dysfunction in essential hypertension: a randomized, double-blind, crossover study. Circulation 2001, 104:511514.

42. Mahmud A, Feely J: Beta-blockers reduce aortic stiffness in hypertension but nebivolol, not atenolol, reduces wave reflection. Am J Hypertens 2008, 21:663-667.

43. Dhakam Z, Yasmin, McEniery CM, Burton T, Brown MJ, Wilkinson IB: A comparison of atenolol and nebivolol in isolated systolic hypertension. J Hypertens 2008, 26:351-356.

44. MacMahon S, Peto R, Cutler J, Collins R, Sorlie $P$, Neaton J, Abbott R, Godwin J, Dyer A, Stamler J: Blood pressure, stroke, and coronary heart disease. Part 1, Prolonged differences in blood pressure: prospective observational studies corrected for the regression dilution bias. Lancet 1990, 335:765-774.

45. Collins R, Peto R, MacMahon S, Hebert P, Fiebach NH, Eberlein KA, Godwin J, Qizilbash N, Taylor JO, Hennekens CH: Blood pressure, stroke, and coronary heart disease. Part 2, Shortterm reductions in blood pressure: overview of randomised drug trials in their epidemiological context. Lancet 1990, 335: 827-838.
46. Johnson AG, Seidemann P, Day RO: NSAID-related adverse drug interactions with clinical relevance. An update. Int $J$ Clin Pharmacol Ther 1994, 32:509-532.

47. Pope JE, Anderson JJ, Felson DT: A meta-analysis of the effects of nonsteroidal anti-inflammatory drugs on blood pressure. Arch Intern Med 1993, 153:477-484.

48. MacDonald TM, Reginster JY, Littlejohn TW, Richard D, Lheritier K, Krammer G, Rebuli R: Effect on blood pressure of lumiracoxib versus ibuprofen in patients with osteoarthritis and controlled hypertension: a randomized trial. J Hypertens 2008, 26: 1695-1702.

49. Aw TJ, Haas SJ, Liew D, Krum H: Meta-analysis of cyclooxygenase-2 inhibitors and their effects on blood pressure. Arch Intern Med 2005, 165:490-496.

50. Aw TJ, Liew D, Tofler GH, Schneider HG, Morel-Kopp MC, Billah $B$, Krum H: Can the blood pressure effects of COX-2 selective inhibitors be explained by changes in plasma aldosterone levels? J Hypertens 2006, 24:1979-1984.

51. Whelton A, White WB, Bello AE, Puma JA, Fort JG: Effects of celecoxib and rofecoxib on blood pressure and edema in patients $>$ or $=65$ years of age with systemic hypertension and osteoarthritis. Am J Cardiol 2002, 90:959-963.

52. Morgan TO, Anderson A, Bertram D: Effect of indomethacin on blood pressure in elderly people with essential hypertension well controlled on amlodipine or enalapril. Am J Hypertens 2000, 13:1161-1167.

53. White WB, Kent J, Taylor A, Verburg KM, Lefkowith JB, Whelton A: Effects of celecoxib on ambulatory blood pressure in hypertensive patients on ACE inhibitors. Hypertension 2002, 39:929-934.

54. Makimattila S, Virkamaki A, Groop PH, Cockcroft J, Utriainen T, Fagerudd J, Yki-Jarvinen $\mathrm{H}$ : Chronic hyperglycemia impairs endothelial function and insulin sensitivity via different mechanisms in insulin-dependent diabetes mellitus. Circulation 1996, 94:1276-1282.

55. Creager MA, Cooke JP, Mendelsohn ME, Gallagher SJ, Coleman SM, Loscalzo J, Dzau VJ: Impaired vasodilation of forearm resistance vessels in hypercholesterolemic humans. J Clin Invest 1990, 86:228-234

56. Panza JA, Quyyumi AA, Brush JE, Jr., Epstein SE: Abnormal endothelium-dependent vascular relaxation in patients with essential hypertension. N Engl J Med 1990, 323:22-27.

57. Heitzer T, Yla-Herttuala S, Luoma J, Kurz S, Munzel T, Just $H$, Olschewski M, Drexler $\mathrm{H}$ : Cigarette smoking potentiates endothelial dysfunction of forearm resistance vessels in patients with hypercholesterolemia. Role of oxidized LDL. Circulation 1996, 93:1346-1353.

58. Taddei S, Virdis A, Mattei P, Ghiadoni L, Gennari A, Fasolo CB, Sudano I, Salvetti A: Aging and endothelial function in normotensive subjects and patients with essential hypertension. Circulation 1995, 91:1981-1987.

59. Schachinger V, Britten MB, Zeiher AM: Prognostic impact of coronary vasodilator dysfunction on adverse long-term outcome of coronary heart disease. Circulation 2000, 101:1899-1906.

60. Suwaidi JA, Hamasaki S, Higano ST, Nishimura RA, Holmes DR, $\mathrm{Jr}$, Lerman A: Long-term follow-up of patients with mild coronary artery disease and endothelial dysfunction. Circulation 2000, 101:948-954

61. Cohn JN, Quyyumi AA, Hollenberg NK, Jamerson KA: Surrogate markers for cardiovascular disease: functional markers. Circulation 2004, 109(Suppl 1):IV31-IV46.

62. Luscher TF: The endothelium and cardiovascular disease: a complex relation. $N$ Engl J Med 1994, 330:1081-1083.

63. Ross R: Atherosclerosis: an inflammatory disease. $N$ Engl J Med 1999, 340:115-126.

64. Hansel S, Lassig G, Pistrosch F, Passauer J: Endothelial dysfunction in young patients with long-term rheumatoid arthritis and low disease activity. Atherosclerosis 2003, 170:177-180.

65. Herbrig K, Haensel S, Oelschlaegel U, Pistrosch F, Foerster S, Passauer J: Endothelial dysfunction in patients with rheumatoid arthritis is associated with a reduced number and impaired function of endothelial progenitor cells. Ann Rheum Dis 2006, 65:157-163

66. Arosio E, De Marchi S, Rigoni A, Prior M, Delva P, Lechi A: Forearm haemodynamics, arterial stiffness and microcirculatory reactivity in rheumatoid arthritis. J Hypertens 2007, 25: 1273-1278. 
67. Wright SA, O'Prey FM, Rea DJ, Plumb RD, Gamble AJ, Leahey WJ, Devine AB, McGivern RC, Johnston DG, Finch MB, Bell AL, McVeigh GE: Microcirculatory hemodynamics and endothelial dysfunction in systemic lupus erythematosus. Arterioscler Thromb Vasc Biol 2006, 26:2281-2287.

68. Piper MK, Raza K, Nuttall SL, Stevens R, Toescu V, Heaton S, Gardner-Medwin J, Hiller L, Martin U, Townend J, Bacon PA, Gordon C: Impaired endothelial function in systemic lupus erythematosus. Lupus 2007, 16:84-88.

69. Gonzalez-Juanatey C, Llorca J, Miranda-Filloy JA, Amigo-Diaz E, Testa A, Garcia-Porrua C, Martin J, Gonzalez-Gay MA: Endothelial dysfunction in psoriatic arthritis patients without clinically evident cardiovascular disease or classic atherosclerosis risk factors. Arthritis Rheum 2007, 57:287-293.

70. Sari I, Okan T, Akar S, Cece H, Altay C, Secil M, Birlik M, Onen F, Akkoc N: Impaired endothelial function in patients with ankylosing spondylitis. Rheumatology (Oxford) 2006, 45:283-286.

71. Miller D, Forrester K, Hart DA, Leonard C, Salo P, Bray RC: Endothelial dysfunction and decreased vascular responsiveness in the anterior cruciate ligament-deficient model of osteoarthritis. J Appl Physiol 2007, 102:1161-1169.

72. O'Driscoll G, Green D, Taylor RR: Simvastatin, an HMG-coenzyme $A$ reductase inhibitor, improves endothelial function within 1 month. Circulation 1997, 95:1126-1131.

73. Randomised trial of cholesterol lowering in 4444 patients with coronary heart disease: the Scandinavian Simvastatin Survival Study (4S). Lancet 1994, 344:1383-1389.

74. Farquharson $C A$, Struthers $A D$ : Spironolactone increases nitric oxide bioactivity, improves endothelial vasodilator dysfunction, and suppresses vascular angiotensin I/angiotensin II conversion in patients with chronic heart failure. Circulation 2000, 101:594-597.

75. The RALES Study Investigators: Effectiveness of spironolactone added to an angiotensin-converting enzyme inhibitor and a loop diuretic for severe chronic congestive heart failure (the Randomized Aldactone Evaluation Study [RALES]). Am J Cardiol 1996, 78:902-907.

76. Husain S, Andrews NP, Mulcahy D, Panza JA, Quyyumi AA: Aspirin improves endothelial dysfunction in atherosclerosis. Circulation 1998, 97:716-720.

77. Mancini GB, Henry GC, Macaya C, O'Neill BJ, Pucillo AL, Carere RG, Wargovich TJ, Mudra H, Lüscher TF, Klibaner MI, Haber HE, Uprichard AC, Pepine CJ, Pitt B: Angiotensin-converting enzyme inhibition with quinapril improves endothelial vasomotor dysfunction in patients with coronary artery disease. The TREND (Trial on Reversing ENdothelial Dysfunction) Study. Circulation 1996, 94:258-265.

78. Taylor AL, Ziesche S, Yancy C, Carson P, D'Agostino R Jr, Ferdinand K, Taylor M, Adams K, Sabolinski M, Worcel M, Cohn JN; African-American Heart Failure Trial Investigators: Combination of isosorbide dinitrate and hydralazine in blacks with heart failure. N Engl J Med 2004, 351:2049-2057.

79. Daiber A, Mülsch A, Hink U, Mollnau H, Warnholtz A, Oelze M, Münzel T: The oxidative stress concept of nitrate tolerance and the antioxidant properties of hydralazine. $A m J$ Cardiol 2005, 96:25i-36i.

80. Nakamura Y, Moss AJ, Brown MW, Kinoshita M, Kawai C: Longterm nitrate use may be deleterious in ischemic heart disease: a study using the databases from two large-scale postinfarction studies. Multicenter Myocardial Ischemia Research Group. Am Heart J 1999, 138:577-585.

81. Wilkinson IB, Webb DJ: Venous occlusion plethysmography in cardiovascular research: methodology and clinical applications. Br J Clin Pharmacol 2001, 52:631-646.

82. Celermajer DS, Sorensen KE, Gooch VM, Spiegelhalter DJ, Miller OI, Sullivan ID, Lloyd JK, Deanfield JE: Non-invasive detection of endothelial dysfunction in children and adults at risk of atherosclerosis. Lancet 1992, 340:1111-1115.

83. Sorensen KE, Celermajer DS, Spiegelhalter DJ, Georgakopoulos D, Robinson J, Thomas O, Deanfield JE: Non-invasive measurement of human endothelium dependent arterial responses: accuracy and reproducibility. Br Heart J 1995, 74:247-253.

84. Wilkinson IB, Hall IR, MacCallum H, Mackenzie IS, McEniery CM, van der Arend BJ, Shu YE, MacKay LS, Webb DJ, Cockcroft JR: Pulse-wave analysis: clinical evaluation of a noninvasive, widely applicable method for assessing endothelial function. Arterioscler Thromb Vasc Biol 2002, 22:147-152.
85. Noon JP, Walker BR, Hand MF, Webb DJ: Impairment of forearm vasodilatation to acetylcholine in hypercholesterolemia is reversed by aspirin. Cardiovasc Res 1998, 38:480484.

86. Monobe $\mathrm{H}$, Yamanari $\mathrm{H}$, Nakamura $\mathrm{K}$, Ohe $\mathrm{T}$ : Effects of low-dose aspirin on endothelial function in hypertensive patients. Clin Cardiol 2001, 24:705-709.

87. Annuk M, Fellstrom B, Lind L: Cyclooxygenase inhibition improves endothelium-dependent vasodilatation in patients with chronic renal failure. Nephrol Dial Transplant 2002, 17: 2159-2163.

88. Wong M, Jiang BY, McNeill K, Farish S, Kirkham B, Chowienczyk $P$ : Effects of selective and non-selective cyclo-oxygenase inhibition on endothelial function in patients with rheumatoid arthritis. Scand J Rheumatol 2007, 36:265-269.

89. Title LM, Giddens K, Mclnerney MM, McQueen MJ, Nassar BA: Effect of cyclooxygenase-2 inhibition with rofecoxib on endothelial dysfunction and inflammatory markers in patients with coronary artery disease. J Am Coll Cardio/ 2003, 42:17471753.

90. Lekakis JP, Vamvakou G, Andreadou I, Ganiatsos G, Karatzis E, Protogerou A, Papaioannou T, Ikonomidis I, Papamichael C, Mavrikakis ME: Divergent effects of rofecoxib on endothelial function and inflammation in acute coronary syndromes. Int $J$ Cardiol 2006, 112:359-366.

91. Bogaty P, Brophy JM, Noel M, Boyer L, Simard S, Bertrand F, Dagenais GR: Impact of prolonged cyclooxygenase-2 inhibition on inflammatory markers and endothelial function in patients with ischemic heart disease and raised C-reactive protein: a randomized placebo-controlled study. Circulation 2004, 110:934-939.

92. Verma S, Raj SR, Shewchuk L, Mather KJ, Anderson TJ: Cyclooxygenase-2 blockade does not impair endothelial vasodilator function in healthy volunteers: randomized evaluation of rofecoxib versus naproxen on endothelium-dependent vasodilatation. Circulation 2001, 104:2879-2882.

93. Bulut D, Liaghat S, Hanefeld C, Koll R, Miebach T, Mugge A: Selective cyclo-oxygenase-2 inhibition with parecoxib acutely impairs endothelium-dependent vasodilatation in patients with essential hypertension. J Hypertens 2003, 21:1663-1667.

94. Chenevard R, Hürlimann D, Béchir M, Enseleit F, Spieker L, Hermann M, Riesen W, Gay S, Gay RE, Neidhart M, Michel B, Lüscher TF, Noll G, Ruschitzka F: Selective COX-2 inhibition improves endothelial function in coronary artery disease. Circulation 2003, 107:405-409.

95. Widlansky ME, Price DT, Gokce N, Eberhardt RT, Duffy SJ, Holbrook M, Maxwell C, Palmisano J, Keaney JF Jr, Morrow JD, Vita JA: Short- and long-term COX-2 inhibition reverses endothelial dysfunction in patients with hypertension. Hypertension 2003, 42:310-315.

96. Gladding PA, Webster MW, Farrell HB, Zeng IS, Park R, Ruijne $\mathrm{N}$ : The antiplatelet effect of six non-steroidal anti-inflammatory drugs and their pharmacodynamic interaction with aspirin in healthy volunteers. Am J Cardiol 2008, 101:10601063.

97. MacDonald TM, Wei L: Effect of ibuprofen on cardioprotective effect of aspirin. Lancet 2003, 361:573-574.

98. Strand V: Are COX-2 inhibitors preferable to non-selective non-steroidal anti-inflammatory drugs in patients with risk of cardiovascular events taking low-dose aspirin? Lancet 2007, 370:2138-2151.

99. del Soldato P, Sorrentino R, Pinto A: NO-aspirins: a class of new anti-inflammatory and antithrombotic agents. Trends Pharmacol Sci 1999, 20:319-323.

100. Berndt G, Grosser N, Hoogstraate J, Schroder H: A common pathway of nitric oxide release from AZD3582 and glyceryl trinitrate. Eur J Pharm Sci 2004, 21:331-335.

101. Fiorucci S, Antonelli E, Santucci L, Morelli O, Miglietti M, Federici B, Mannucci R, Del Soldato P, Morelli A: Gastrointestinal safety of nitric oxide-derived aspirin is related to inhibition of ICElike cysteine proteases in rats. Gastroenterology 1999, 116: 1089-1106.

102. al-Swayeh OA, Clifford RH, del Soldato P, Moore PK: A comparison of the anti-inflammatory and anti-nociceptive activity of nitroaspirin and aspirin. Br J Pharmacol 2000, 129:343-350.

103. Cuzzolin L, Conforti A, Adami A, Lussignoli S, Menestrina F, Del Soldato $\mathrm{P}$, Benoni G: Anti-inflammatory potency and gastroin- 
testinal toxicity of a new compound, nitronaproxen. Pharmacol Res 1995, 31:61-65.

104. Wallace JL, McKnight W, Del Soldato P, Baydoun AR, Cirino G: Anti-thrombotic effects of a nitric oxide-releasing, gastricsparing aspirin derivative. J Clin Invest 1995, 96:2711-2718.

105. Keeble J, Al-Swayeh OA, Moore PK: Vasorelaxant effect of nitric oxide releasing steroidal and nonsteroidal anti-inflammatory drugs. Br J Pharmaco/ 2001, 133:1023-1028.

106. Muscara MN, McKnight W, Del Soldato P, Wallace JL: Effect of a nitric oxide-releasing naproxen derivative on hypertension and gastric damage induced by chronic nitric oxide inhibition in the rat. Life Sci 1998, 62:PL235-PL240.

107. Schnitzer TJ, Kivitz AJ, Lipetz RS, Sanders N, Hee A: Comparison of the COX-inhibiting nitric oxide donator AZD3582 and rofecoxib in treating the signs and symptoms of Osteoarthritis of the knee. Arthritis Rheum 2005, 53:827-837.

108. Schnitzer TJ, Kivitz A, Rankin B, Fisher C, Fishman R, Marker $\mathrm{H}$, Frayssinet $H$, Duquesroix B: Comparison of naproxcinod to naproxen and placebo: Results of a 13-week phase 3 pivotal trial in paients with osteoarthritis of the knee with particular focus on blood pressure effects. Ann Rheum Dis 2008, 67 (suppl II):394

109. Towsend R, Bittar N, Rosen J, Smith W, Ransay A, Chrysant S, Weiss R, Frayssinet $H$, Duquesroix B: Differential blood pressure effect of naproxcinod compared with naproxen: 24-hour blood pressure profile in stable hypertensive subjects. Ann Rheum Dis 2008, 67(suppl II):631.

110. Johnson AG, Nguyen TV, Day RO: Do nonsteroidal anti-inflammatory drugs affect blood pressure? A meta-analysis. Ann Intern Med 1994, 121:289-300.

111. Calhoun DA, Jones D, Textor S, Goff DC, Murphy TP, Toto RD, White A, Cushman WC, White W, Sica D, Ferdinand K, Giles TD, Falkner B, Carey RM; American Heart Association Professional Education Committee: Resistant hypertension: diagnosis, evaluation, and treatment: a scientific statement from the American Heart Association Professional Education Committee of the Council for High Blood Pressure Research. Circulation 2008, 117:e510-526.

112. Morrison A, Ramey DR, van Adelsberg J, Watson DJ: Systematic review of trials of the effect of continued use of oral nonselective NSAIDs on blood pressure and hypertension. Curr Med Res Opin 2007, 23:2395-2404.

113. Rossoni G, Muscara MN, Cirino G, Wallace JL: Inhibition of cyclo-oxygenase-2 exacerbates ischaemia-induced acute myocardial dysfunction in the rabbit. $\mathrm{Br} J$ Pharmacol 2002, 135:1540-1546.

114. Rossoni G, Manfredi B, Del Soldato P, Berti F: The nitric oxidereleasing naproxen derivative displays cardioprotection in perfused rabbit heart submitted to ischemia-reperfusion. J Pharmacol Exp Ther 2004, 310:555-562.

115. Lüscher TF, Barton M: Endothelins and endothelin receptor antagonists: therapeutic considerations for a novel class of cardiovascular drugs. Circulation 2000, 102:2434-2440. 